\title{
EXIT DISCRIMINATION IN MAJOR LEAGUE BASEBALL: 1990-2004
}

Peter A. Groothuis

Associate Professor

Department of Economics

Appalachian State University

Boone, NC 28607

groothuispa@appstate.edu

and

James Richard Hill

Professor

Department of Economics

Central Michigan University

Mt Pleasant, MI 48858

hill1jr@cmich.edu 


\begin{abstract}
Using a panel study of annual Major League Baseball data (1990-2004) we do not find evidence of exit discrimination against African-American players in Major League Baseball. Our findings are inconsistent with results from a study by Jiobu (1988) using 1971-1985 data which found that race decreased career length, ceteris paribus, for black players but not Hispanics. Our results are consistent with recent findings that failed to find evidence of exit discrimination in the NBA using data from the 1990s. In our semi-parametric duration analysis, we find that performance variables are important in determining career length. We find no evidence that race affects the career duration of black hitters. Past research had suggested that discrimination by majority, white fans led owners in sports to keep less talented white players on rosters. Our results suggest that team owners in the pursuit of championships keep talented players regardless of race. This is an affirmation of Becker's theoretical implications of market competition overcoming discrimination.
\end{abstract}




\section{Introduction}

The topic of discrimination in labor markets has attracted a great deal of research by economists over time. From the theoretical constructs developed by Gary Becker (1971) to the development of the residual method by Ronald Oaxaca (1973) economists have struggled to determine the cause and effects of prejudice on minority workers. Professional sports have provided a fertile field for researchers of this topic because of the abundance of performance data and salary information available. In Lawrence Kahn's 1991 article on discrimination in professional sports he reviews empirical findings from numerous articles published between 1972 and 1989. He divides his summaries under four major headings: salary discrimination, positional discrimination, customer discrimination, and hiring discrimination. Many of the articles offered findings on more than one of the topic headings.

Salary discrimination drew the most attention. Twenty four articles with empirical work on this topic are critiqued by Kahn (1991): twelve on baseball, eight on basketball, and two each on football and hockey. The strongest evidence of salary discrimination against black athletes comes from studies of the NBA based on data from the 1984-1986 timeframe. However more recent research (Hill (2004) and Bodvarsson and Brastow (1999)) has failed to find salary discrimination in the NBA using data from the 1990s. Twelve articles involving research on positional segregation were reviewed (Kahn 1991): five from baseball, three from football, two from basketball, and two from hockey. Evidence suggested positional segregation or stacking existed for blacks in baseball and football; evidence also suggested that blacks were underrepresented at the center and forward position in the NBA. Customer discrimination was the main or auxiliary focus in fifteen of the papers (Kahn 1991): nine from basketball and six from baseball. Results are mixed for attendance at NBA games; a recent article (Kanazawa and Funk (2001)) finds a negative correlation between the percentage of blacks on the roster and cable TV ratings. 
In baseball, evidence from mid-1970s revenue data fails to find customer discrimination but studies using earlier data did. Customer discrimination also appears to exist in the baseball trading card market (Nardinelli and Simon (1989)).

Of the thirteen pieces of empirical work focused on hiring discrimination reviewed by Kahn (1991), six deal with data from baseball, four with basketball, two with hockey, and one with football. Findings failed to confirm hiring barriers for black athletes in basketball and baseball; whites with inferior performances were not hired over superior black athletes. However, Johnson and Marple (1973) found evidence from 197071 NBA data that marginal white players had longer careers than marginal black players. Hoang and Rascher (1999) explored the concept of racially-based retention barriers in the NBA in more detail using data from the 1980s. They, too, found evidence that, holding performance constant, there was "exit discrimination” in the NBA. Groothuis and Hill (2004) failed to confirm Hoang and Rascher’s results using more recent data, height as an added explanatory variable, and a duration model that allowed for both stock and flow samples.

Jiobu (1988) found evidence that race decreased career length, ceteris paribus, for black players but not Hispanics using Major League baseball from 1971-1985 data. The purpose of this article is determine if Jiobu's findings can be replicated using more recent baseball data and a richer duration model that has season-variant data; Jiobu used only unchanging, career performance variables in his model. Exit discrimination is more subtle than positional segregation or pay discrimination. If exit discrimination in Major League baseball is no longer present it would seem to affirm Becker's theoretical implications that market competition will eliminate discrimination over time. 


\section{Theory}

Discrimination in the labor market implies that certain individuals or groups of workers are somehow treated differently than others unrelated to ability or performance; in the literature on professional sports the focus has been on differential treatment of black and Hispanic players. The differential treatment can occur in a variety of formats. When pay discrimination occurs workers in the group receiving the unequal treatment receive lower pay than others for the same performance level. Most researchers believe pay discrimination against black players in professional baseball was eventually eliminated by free agency and salary arbitration in the mid-1970s (Hill and Spellman (1984) and Cymrot (1985).

Hoang and Rascher (1999) define exit discrimination as "the involuntary dismissal of workers based on the preferences of employers, coworkers, or customers.” Jiobu (1988) and Hoang and Rascher (1999) concluded that career length for black players in Major League baseball and the NBA respectively were lower than their white counterparts, ceteris paribus. While Jiobu does not make any calculations on the impact of exit discrimination on career earnings, Hoang and Rascher (1999) conclude that this form of discrimination led to almost a two and a half times greater decrease in black career pay compared to the more heavily analyzed form of pay discrimination.

Becker (1971) suggests that the source of the personal prejudice that leads to various forms of labor market discrimination may be employers, coworkers or customers. Recent research by Kahn and Sherer (1988) on pay discrimination in the NBA and Hoang and Rascher (1999) on exit discrimination in the NBA has focused on customers as the source of the prejudice; both studies found empirical evidence to support the existence of customer discrimination. The pay premium for white players was explained by the 
higher value of their performances compared to black players because of the prejudiced preferences of white, majority fans.

Hoang and Rascher (1999, p.74)) hypothesized:

"To satisfy the fans, there is a minimum number of white players on a team. The second assumption, that the pool of quality available talent is becoming increasingly black, causes annual replacement of players with rookies to occur mostly among black players. The white players have longer careers simply because there are fewer qualified white rookies to replace them,..."

In his study of exit discrimination in Major League baseball, Jiobu (1988, p.532) does not specifically test for customer discrimination but he does state:

"Perhaps, motivated by the concern that white fans will not support a predominantly black team, management has silently placed an "invisible ceiling" on the black percentage. When coupled with the desire to have a winning team, this ceiling would generate strong pressures to (a) employ as many black players as possible in order to capitalize on their performance, but (b) in order to remain under the ceiling, to eliminate black players as soon as their performance declined, and (c) to retain white players of declining but similar ability.”

Research on this topic assumes that all turnover is involuntary; Kahn (1991, p. 406) argues that the high salaries paid in sports make voluntary quits unlikely. Thus these studies are essentially survival models. If white players have longer careers than black players with similar performance statistics then exit discrimination is said to exist.

\section{Data}

Our data includes all individuals, both hitters and pitchers, who participated in Major League Baseball from 1990 through 2004 for a fifteen-year panel consisting of 3185 players. Jiobu's (1988) study on exit discrimination in baseball only looked at hitters. To capture the overall length of players' baseball careers our data consists of both stock and flow samples. (See figure 1.) A stock sample consists of all ongoing careers at the start of the panel in 1990. These left-censored data are easily included because we know how many years each player had played in the Majors prior to 1990. Our stock sample consists of 690 players who had an average tenure of six years as they entered the 
1990 season. Including a stock sample captures information on players who careers are longer than the panel data set. Using only stock data, however, would under represent short-career players, so we also include flow data.

A flow sample includes all careers that start between 1990 and 2004. This sample captures many short careers in Major League Baseball. Including only flow data however would allow for no careers longer than 15 years, which is the length of our panel. As with most panels our data is also right-censored where many careers were ongoing when our sample ended in 2004. Our right-censored data includes both stock and flow observations. To estimate a duration model of stock and flow data, we use a technique developed by Berger and Black (1999).

The variables in our data include both season-variant and season-invariant data. Jiobu (1988) used only season-invariant data for his analysis. We report the means in Table 1A for hitters and Table 1B for pitchers. Our season-invariant data include dummy variables for player's race, a dummy variable for infielders, first basemen, and catchers, and a dummy variable for pitcher's throwing hand. Our season-variant data for hitters are age and performance data that include games played as well as slugging average, stolen base percentage, runs batted in per game, walks per game, strikeouts per game, hit by pitch per game, sacrifice flies per game, and runs scored per game. Our season-variant data for pitchers are age and performance data that include games played as well as earned run average, wins, losses, saves, strikeout-to-walk ratio, and outs in innings pitched. In Tables $1 \mathrm{~A}$ and $1 \mathrm{~B}$ we report variable means by race. To determine if exit discrimination exits in the Major Leagues we analyze the data using both nonparametric and semi-parametric techniques. 


\section{Model: Non-parametric Estimates of Career Duration}

To help understand career duration in Major League Baseball, we calculate yearly hazard functions as:

$$
h_{t}=d_{t} / n_{t}
$$

where $d_{t}$ is the number of players who end their career in year $t$ and $n_{t}$ is the number of players at risk of ending their career in year t. The hazard rate can be interpreted as the percentage of players who exited the MLB given they have survived up to some level of tenure. In table 2, we report the hazard rate for foreign-born Hispanic, black, and white hitters.

In Figure 2 we plot the hazard functions for hitters by race where series 1 is the hazard rate for African-American players, series 2 the hazard rate for foreign-born Latino players and series 3 is the hazard rate for white players. All three plots show the hazard rate gradually declines for the first seven years of tenure in the MLB and then gradually climbs for the remainder of the years. In addition both hazard plots follow an interesting pattern that resembles a u-shape. In the engineering literature on useful life this hazard function shape has become known as the "bathtub" plot. In this literature, the initial downturn is identified as infant mortality, the bottom of the tub due to random failure, and the upturn due to wear-out (Bolla 2002). We suggest that this pattern also explains an MLB career with the initial downturn occurring as individuals are sorted from the league and the upturn due to wear-out from the physical demands of playing baseball.

Comparing the three plots shows many crosses. The hazard plot suggests that the hazard rates for black, foreign-born Hispanic, and white players are similar. ${ }^{1}$ Interpreting the differences in hazard rates as discrimination, however, is misleading. The problem arises for the same reason using differences in median wage is misleading in the wage

\footnotetext{
${ }^{1}$ Hazard rates and plots are available for pitchers as well.
} 
literature: neither method controls for differences due to productivity. In the next section we analyze career duration using semi-parametric techniques to control for differences in productivity.

\section{Model: Semi-parametric Estimates of Career Duration}

We estimate semi-parametric hazard functions following Berger and Black (1999) Groothuis and Hill (2004) and Berger, Black and Scott (2004). Because our data is at the season level we calculate our hazard model as a discrete random variable. As with Black, Berger and Scott (2004), we model the durations of a single spell and assume a homogeneous environment so that the length of the spell is uncorrelated with the calendar time in which the spell begins. This assumption lets us treat all the players' tenure as the same regardless of when it occurred in the panel study. For instance, all fourth year players are considered to have the same base line hazard regardless of calendar time so a fourth year player in 1990 has the same baseline hazard as a fourth year player 1997.

To understand how stock data influences a likelihood function we follow the notation of Berger, Black, and Scott (2001). Suppose the probability mass function (pmf) of durations is defined as:

$$
f(t, x, \beta) \text {, }
$$

where $\mathrm{t}$ is the duration of the career, $\mathrm{x}$ is a vector of performance and personal characteristics, and $\beta$ is a vector of parameters. Now denote $F(t, x, \beta)$ as the cumulative distribution function; then the probability that a career lasts at least $t^{\circ}$ years is simply 1 $\mathrm{F}\left(\mathrm{t}^{\circ}, \mathrm{x}, \beta\right)$. If we define the hazard function as $\mathrm{h}(\mathrm{t}, \mathrm{x}, \beta) \equiv \mathrm{f}(\mathrm{t}, \mathrm{x}, \beta) / \mathrm{S}(\mathrm{t}, \mathrm{x}, \beta)$ and apply the definition of conditional probabilities, we may express the pmf as

$$
f\left(t_{i}, x_{i}, \beta\right)=\prod_{j=0}^{t_{i}-1}\left[1-h\left(j, x_{i}, \beta\right)\right] h\left(t_{i}, x_{i}, \beta\right) .
$$


If we have a sample of $n$ observations, $\left\{t_{1}, t_{2}, \ldots, t_{n}\right\}$, the likelihood function of the sample is

$$
L(\beta)=\prod_{i=1}^{n} f\left(t_{i}, x_{i}, \beta\right)=\prod_{i=1}^{n}\left(\prod_{j=1}^{t_{i}-1}\left[1-h\left(j, x_{i}, \beta\right)\right] h\left(t_{i}, x_{i}, \beta\right)\right) .
$$

Often it is not possible to observe all careers until they end, hence careers are often rightcensored. Let the set A be the set of all observations where the players' careers are completed and the set $\mathrm{B}$ be the set of all observations where the careers are right censored. In this case A and B are disjoint sets whose union is exactly the set of observation. For the set of right-censored observations, all we know is that the actual length of the career is greater than $t_{i}$, the observed length of the career up through the last year. Because we know that the actual length of the career is longer than we observe then the contribution of these observations to the likelihood function is just the survivor function, $S\left(t_{i}, x_{i}, \beta\right)$. Thus, we may write the likelihood function as

$$
\begin{aligned}
L(\beta) & =\prod_{i \in A}\left(\prod_{j=1}^{t_{i}-1}\left[1-h\left(j, x_{i}, \beta\right)\right] h\left(t_{i}, x_{i}, \beta\right)\right) \times \prod_{i \in B} S\left(t_{i}, x_{i}, \beta\right) \\
& =\prod_{i \in A}\left(\prod_{j=1}^{t_{i}-1}\left[1-h\left(j, x_{i}, \beta\right)\right] h\left(t_{i}, x_{i}, \beta\right)\right) \times \prod_{i \in B}\left(\prod_{j=1}^{t_{i}-1}\left[1-h\left(j, x_{i}, \beta\right)\right]\right)
\end{aligned}
$$

where equation (5) exploits the property that $S(t, x, \beta)=\prod_{i=1}^{t-1}[1-h(i, x, \beta)]$. Equation (5) is the likelihood function for any flow sample of discrete durations.

To introduce stock sampling, let the set $\mathrm{C}$ be the set of careers that were in progress when data collection began. For these observations, we know that the career i has lasted for $r$ years before the panel begins so that the probability that the total career length will be $\mathrm{t}$ is simply given by

$$
\frac{f(t, x, \beta)}{S(r, x, \beta)}=\left(\prod_{i=r}^{t-1}[1-h(i, x, \beta)]\right) h(t, x, \beta) .
$$


Because we are sampling careers that are already in progress, these observations enter the sample only if the career is at least of length $r$, and hence we must adjust by the conditional probability of the career having length $r$. With the addition of these observations, we may write the likelihood function as

$$
\begin{aligned}
L(\beta)=\prod_{i \in A}\left(\prod_{j=1}^{t_{i}-1}\left[1-h\left(j, x_{i}, \beta\right)\right] h\left(t_{i}, x_{i}, \beta\right)\right) \times \prod_{i \in B}\left(\prod_{j=1}^{t_{i}-1}\left[1-h\left(j, x_{i}, \beta\right)\right]\right) \\
\times \prod_{i \in C}\left(\prod_{j=r_{i}}^{t_{i}-1}\left[1-h\left(j, x_{i}, \beta\right)\right]\right) h\left(t_{i}, x_{i}, \beta\right)
\end{aligned}
$$

The third term of the right-hand side of equation (7) reflects the adjustment necessary for the stock sample that end during our panel. Because stock-sampled observations, by definition, must have survived until tenure r, which they survived until time r provides no information; their survival is an artifact of the sampling strategy.

Of course, some stock-sampled observations may be right-hand censored. Let the set $\mathrm{D}$ be the set of all stock-sampled observations that are also right-hand censored. An example of a career that is both right and left censored would be a player that starts his career prior to 1990 and ends his career after 2004. A stock-sampled observation that is right-hand censored at time t occurs with probability

$$
\frac{S(t, x, \beta)}{S(r, x, \beta)}=\prod_{j=r}^{t-1}[1-h(j, x, \beta)],
$$

so that the likelihood function becomes

$$
\begin{aligned}
L(\beta)=\prod_{i \in A}\left(\prod_{j=1}^{t_{i}-1}\left[1-h\left(j, x_{i}, \beta\right)\right] h\left(t_{i}, x_{i}, \beta\right)\right) \times \prod_{i \in B}\left(\prod_{j=1}^{t_{i}-1}\left[1-h\left(j, x_{i}, \beta\right)\right]\right) \\
\times \prod_{i \in C}\left(\prod_{j=r_{i}}^{t_{i}-1}\left[1-h\left(j, x_{i}, \beta\right)\right]\right) h\left(t_{i}, x_{i}, \beta\right) \times \prod_{i \in D}\left(\prod_{j=r_{i}}^{t_{i}-1}\left[1-h\left(j, x_{i}, \beta\right)\right]\right)
\end{aligned}
$$


In equation (9), the contribution of censored, stock-sampled observations to the likelihood function is strictly from the last two terms; such observations simply provide information about the survivor function between $(\mathrm{r}, \mathrm{t})$.

Thus we, as Berger, Black and Scott (2004), have expressed the likelihood function as a function of the hazard functions. All that remains is to specify the form of a hazard function and estimate by means of maximum likelihood estimation. As the hazard function is the conditional probability of exiting the MLB given that the MLB career lasted until the previous season, the hazard function must have a range from zero to one. In principle, any mapping with a range from zero to one will work. Cox (1972) recommends

$$
\frac{h(t, x, \beta)}{1-h(t, x, \beta)}=\frac{h_{t}}{1-h_{t}} e^{x \beta}=\exp \left(\gamma_{t}+x \beta\right),
$$

which is simply the logit model with intercepts that differ by time periods. The term $h_{t}$ is a baseline hazard function, which is common to all. The $\mathrm{x} \beta$ term, determined by the player's personal and productivity characteristics, shifts the baseline hazard function, but it affects the baseline hazard function in exactly the same way each period. Berger and Black (1999) consider other hazard functions and find that the results are relatively robust across various specifications of the hazard function. As the logit model is available in many software packages, we follow Cox and use the logit model.

The intuition behind equation (10), when using the logit model for the hazard function, is relatively simple. For each year during the survey in which the player is in the MLB, the player either comes back for another season or ends his career. If the career ends, the dependent variable takes on a value of one; otherwise, the dependent variable is zero. The player remains in the panel until the player exits the MLB or the panel ends. If the panel ends, we say the worker's spell is right-hand censored. Thus a 
player who begins his MLB career during the panel and plays for 6 years will enter the data set 6 times: the value of his dependent variable will be zero for the first 5 years (tenure one through five) and be equal to one for the sixth year.

To illustrate a stock sample consider another player who enters the panel with 7 years of MLB job tenure prior to 1990 the first year of the panel, then plays for an additional 3 years for a 10 year career. For this player, we ignore his first 7 years of tenure because he is left-hand censored. As the equation of the likelihood function with stock data indicates, the duration of a MLB career prior to the beginning of the panel makes no contribution to the value of the likelihood function. Therefore only years 8 through 10 will enter the data set with the dependent variable taking on the value zero for year 8 and 9 and in the $10^{\text {th }}$ year it takes on a value of one with this player appearing in the data set a total of 3 times. Note for all players who are right-hand censored, we do not know when their career ends so their dependent variables are always coded as zero.

Because the players in the panel have varying degrees of job tenure prior to the beginning of the panel, we identify the hazard function for both long and short careers. The disadvantage to this approach is that the vector $\gamma_{t}$ of equation (10) can be very large. In our study it would require 25 dummy variables. We also run into problems with the Cox technique because we have too few players who have long careers. To simplify the computation of the likelihood function and be able to keep the long careers, we simply approximate the $\gamma_{\mathrm{t}}$ vector with a $5^{\text {th }}$ order polynomial of player's tenure, which reduces the number of parameters to be estimated from 25 to 5 . Thus, the hazard function becomes

$$
\frac{h(t, x, \beta)}{1-h(t, x, \beta)}=\Phi(t) e^{x \beta}=\exp (\phi(t)+x \beta)
$$


where $\phi(t)$ is a $5^{\text {th }}$ order polynomial in the worker's tenure. Once again, we choose the Taylor series approximation technique over using tenure dummies due to the small number of observations for high tenures. This method provides a very flexible specification of the baseline hazard, but does impose more restrictions than Cox's model. $^{2}$

In Table 3A, we report the estimates for hitters for equation 11. In the model we find that the tenure polynomials are jointly significant. In our model of exit, we suggest that performance should increase career length. Owners will keep players who are productive. All our specifications results support this prediction where we find performance measures are important in career duration. In particular the number of games played in a season, the number of runs scored per game, slugging percentage, runs batted in per game, and stolen base percentage all significantly increase the likelihood of remaining in the major league baseball for another season. Strikeouts per game decreases duration; it is significant. Walks per game and sacrifice flies per game are improperly signed but not significant; hit by a pitch per game is properly signed but not significant. Exit probability rises significantly with player age. Both infielders and catchers enjoy longer playing careers ceteris paribus than outfielders (excluded category) and first basemen. This is not surprising since these positions are viewed more as defensive in nature whereas first basemen and outfielders are generally viewed as more offensive positions and offensive contributions are already captured by the performance statistics included in the model.

In our model of exit, we also suggest that race may play a role if white customers have a preference to see white players and teams find it difficult to replace white players. Our results for hitters, however, do not support this claim. Only the coefficient for

\footnotetext{
${ }^{2}$ When higher order polynomials of the sixth and seventh power are included results do not change suggesting that a fifth order polynomial is flexible enough to capture the influence of the base line hazard.
} 
foreign-born Latino players is positive, meaning this attribute increases the probability of exit for the time period. However, the coefficient is not significant. The coefficients for the other race dummy variables are all negative, indicating members of these groups have lower probability of exit. All coefficients are insignificant. In order to convert the coefficient into a percentage and focus on the magnitude of the effect we use $100[\exp (\beta)$ -1]. This conversion gives us the percentage difference in hazard rates between whites and black, between whites and foreign born Hispanics and between whites and American born Hispanics. We find that black hitters have a $13 \%$ percent lower hazard rate than white hitters while foreign-born Hispanic hitters have a 15\% percent higher hazard rate than whites. Asian-born hitters, a very small percentage of the sample, have a 59\% lower hazard rate than white hitters. All results are statistically insignificant.

These results are contrary to Jiobu's finding of exit discrimination for black players. Several explanations for the difference in results can be posited. First, our data covers a more recent time period. Perhaps competitive market forces have removed this vestige of discrimination from Major League Baseball. Second, while our econometric technique is similar in nature to that of Jiobu, he used only career performance statistics. None of his data varied between seasons. Therefore, his finding of exit discrimination rests solely on the higher average career performance statistics of black hitters versus white hitters and the average duration of each race. Jiobu finds longer career length on average for black hitters but finds a positive and significant coefficient for his black dummy variable in the duration analysis. This would seem a foregone conclusion given their higher average career statistics and longer career lengths. Our model has yearly performance statistics that allow the duration analysis to adjust for the "decay rate” of hitter skills. 
In Table 3B, we report the estimates for pitchers for equation 11 . The tenure polynomials are jointly significant again. The coefficients of all of the performance measures are properly signed and significant determinants of career duration. Increases in earned run average and losses increase the probability of exit while increase in wins, saves, strike-out to walk ratio, outs in innings pitched, and games played decrease the probability of exit. Left-handed pitchers enjoy longer careers, ceteris paribus, than righthanders. As with hitters, exit probability rises with player age.

Results for the race coefficients are perplexing. The coefficient for the black dummy is positive but insignificant; the coefficient for Asian-born players is negative but insignificant. The coefficients for Foreign-born Latinos are negative and significant. This statistical anomaly is hard to explain; Latino pitchers have longer career lengths than warranted by their performance statistics.

Once again, in order to convert the coefficient into a percentage and focus on the magnitude of the effect we use $100[\exp (\beta)-1]$. This conversion gives us the percentage difference in hazard rates between whites and black. Here we find that black pitchers have a $7.6 \%$ percent higher hazard rate than whites although it is insignificant. On the other hand, however, foreign-born Hispanic pitchers have lower hazard rates than white pitchers. Foreign-born Hispanic pitchers have a 20.1\% lower hazard rate; the difference is statistically significant. Asian-born pitchers, a very small percentage of the sample, have a $22.5 \%$ lower hazard rate than white pitchers but this difference is not statistically significant.

\section{Conclusion}

Our findings are inconsistent with results from a study by Jiobu (1988) in a prominent sociology journal (Social Forces) using 1971-1985 data which found that race decreased career length, ceteris paribus, for black players but not Hispanics. Our results are 
consistent with recent findings that failed to find evidence of exit discrimination in the NBA using data from the 1990s. In our semi-parametric duration analysis, we find that performance variables are important in determining career length. We find not evidence that race affects the career duration of black hitters; we find the anomalous result that foreign-born Latino pitchers have longer career lengths than warranted by their performance statistics. Past research had suggested that discrimination by majority, white fans led owners in sports to keep less talented white players on rosters. Our results, with the aforementioned anomaly noted, suggest that team owners in the pursuit of championships keep talented players regardless of race. This is an affirmation of Becker's theoretical implications of market competition overcoming discrimination. 


\section{References}

1. Becker, Gary, The Economics of Discrimination, 2nd Ed. Chicago: University of Chicago Press, 1971.

2. Berger, Mark C., and Dan. A. Black. "The Duration of Medicaid Spells: An Analysis Using Flow and Stock Samples" The Review of Economics and Statistics, 80(4), 1999, 667-74.

3. Bodvarsson, Orn, B. and Ramond T. Brastow, "A Test of Employer Discrimination in the NBA." Contemporary Economic Policy, 17 (1999), pp.243-255.

4. Bolla, G. A. "Accelerated Useful Life Testing and Field Correction Methods," Visteon Corporation Paper, Society of Automotive Engineers, 2002.

5. Bratsberg, B., and D. Terrell. "Experience, Tenure, and Wage Growth of Young Black and White Men" Journal of Human Resources, 33(3), 1998, 658-82.

6. Cymrot, Donald J.,"Does Competition Lessen Discrimination? Some Evidence" Journal of Human Resources, (Fall 1985), pp.605-612.

7. Groothuis, Peter A. and J. Richard Hill, 2004, "Exit Discrimination in the NBA: A Duration Analysis of Career Length Using Flow and Stock Samples", Economic Inquiry, 42 (2004) pp. 341-349.

8. Hill, James Richard and William Spellman, "Pay Discrimination in Baseball: Data from the Seventies,” Industrial Relations, 23 (1984) pp.103-112.

9. Hoang, Ha and Dan Rascher, "The NBA, Exit Discrimination, and Career Earnings" Industrial Relations, 38 (1999) pp. 69-91.

10. Jiobu, Robert M., "Racial Inequality in a Public Arena: The Case of Professional Baseball” Social Forces, 67 (December 1988) pp. 524-534.

11. Johnson, Norris R., and David P.Marple, "Racial Discrimination in Professional Basketball: An Empirical Test" Sociological Focus, (Fall 1973), pp. 6-18.

12. Kahn, Lawrence M., "The Sports Business as a Labor Market Laboratory" Journal of Economic Perspectives, 14 (2000), pp.75-94.

13. Kahn, Lawrence M., "Discrimination in Professional Sports: A Survey of the Literature" Industrial and Labor Relations Review, (April 1991), pp. 395-418.

14. Kahn, Lawrence M. and Peter D. Sherer, "Racial Differences in Professional Basketball Players Compensation" Journal of Labor Economics, (January 1988) pp. 40-61. 
15. Kanazawa, Mark T., and Jonas P. Funk, "Racial discrimination in professional basketball: evidence from the Nielsen ratings" Economic Inquiry, (Oct. 2001) p. 599-608.

16. Kaufman, Bruce E. and Julie L. Hotchkiss, The Economics of Labor Markets, Sixth Edition, Chapter Nine, (Thomson 2003).

17. Koch, James V. and C. Warren Vander Hill "Is There Discrimination in the 'Black Man's Game'?" Social Science Quarterly, 69 (1988), pp.83-94.

18. Oaxaca, Ronald. 1973. "Male-Female Wage Differentials in Urban Labor Markets" International Economic Review, 14 (1973), pp.693-709.

19. Sexton, E. A., and R. Neil Olsen. "The Returns to On-the-Job Training: Are They the Same for Blacks ands Whites?" Southern Economic Journal, 61(2), 1994, 328-42.

20. Smith, J. P., and F. R. Welch. "Black Economic Progress After Myrdal" Journal of Economic Literature, 27(2), 1989, 519-64. 
Figure 1:

\section{Panel Data of Stock and Flow Data}

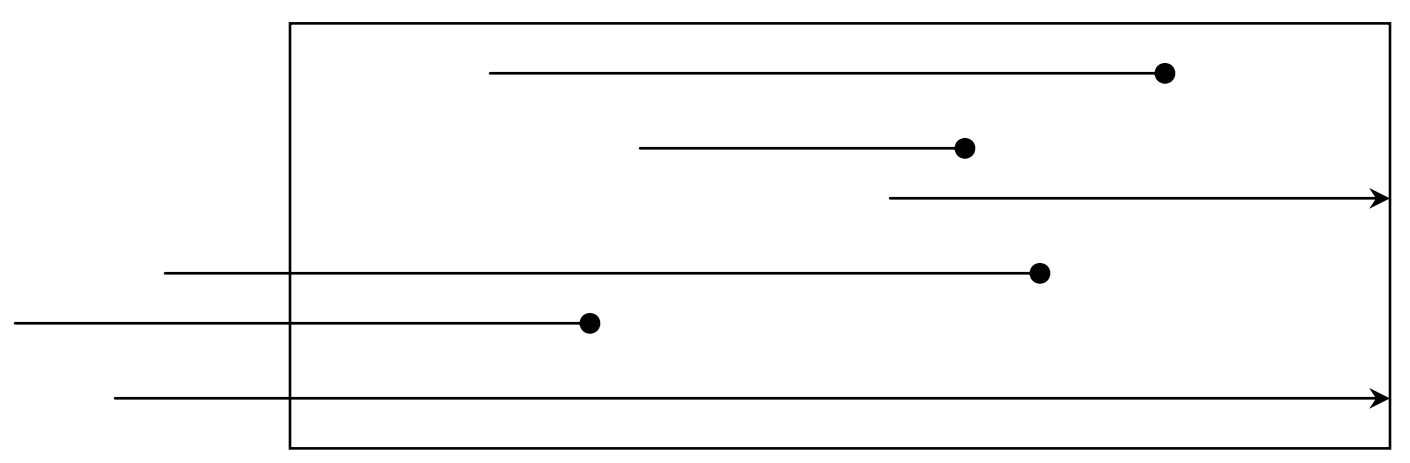

Left censored Right censored 
Table 1A

Hitter Panel Data (1990-2004): Means of Variables

\begin{tabular}{|l|l|l|l|}
\hline Variables & White & Black & $\begin{array}{l}\text { Foreign-Born } \\
\text { Latinos }\end{array}$ \\
\hline Age & 29.55 & 29.82 & 27.97 \\
\hline Slugging Average & .394 & .404 & .395 \\
\hline Stolen Base Percentage & 3.70 & 10.61 & 6.17 \\
\hline Runs Batted In per game & .369 & .386 & .385 \\
\hline Walks per game & .295 & .313 & .261 \\
\hline Strike-Outs per game & .540 & .552 & .549 \\
\hline Hit by Pitch per game & .028 & .024 & .027 \\
\hline Sacrifice Flies per game & .026 & .025 & .025 \\
\hline Runs Scored per game & .378 & .441 & .407 \\
\hline Games & 93.02 & 102.54 & 98.52 \\
\hline Infield & .397 & .204 & .493 \\
\hline Catcher & .221 & .016 & .142 \\
\hline First Base & .125 & .088 & .065 \\
\hline
\end{tabular}

Table 1B

Pitcher Panel Data (1990-2004): Means of Variables

\begin{tabular}{|l|l|l|l|}
\hline Variables & White & Black & $\begin{array}{l}\text { Foreign- } \\
\text { Born } \\
\text { Latinos }\end{array}$ \\
\hline Age & 29.08 & 28.44 & 27.61 \\
\hline Earned Run Average & 4.731 & 4.848 & 4.775 \\
\hline Wins & 4.793 & 4.789 & 4.891 \\
\hline Losses & 4.758 & 4.562 & 4.763 \\
\hline Saves & 2.316 & 3.117 & 2.834 \\
\hline Strike Out to Walk Ratio & 1.903 & 1.723 & 1.940 \\
\hline Outs in innings pitched & 256.226 & 248.789 & 256.969 \\
\hline Games & 32.49 & 34.17 & 34.08 \\
\hline Left-handed & .311 & .227 & .197 \\
\hline
\end{tabular}


Figure 2A: Hazard Rates for Major League Hitters

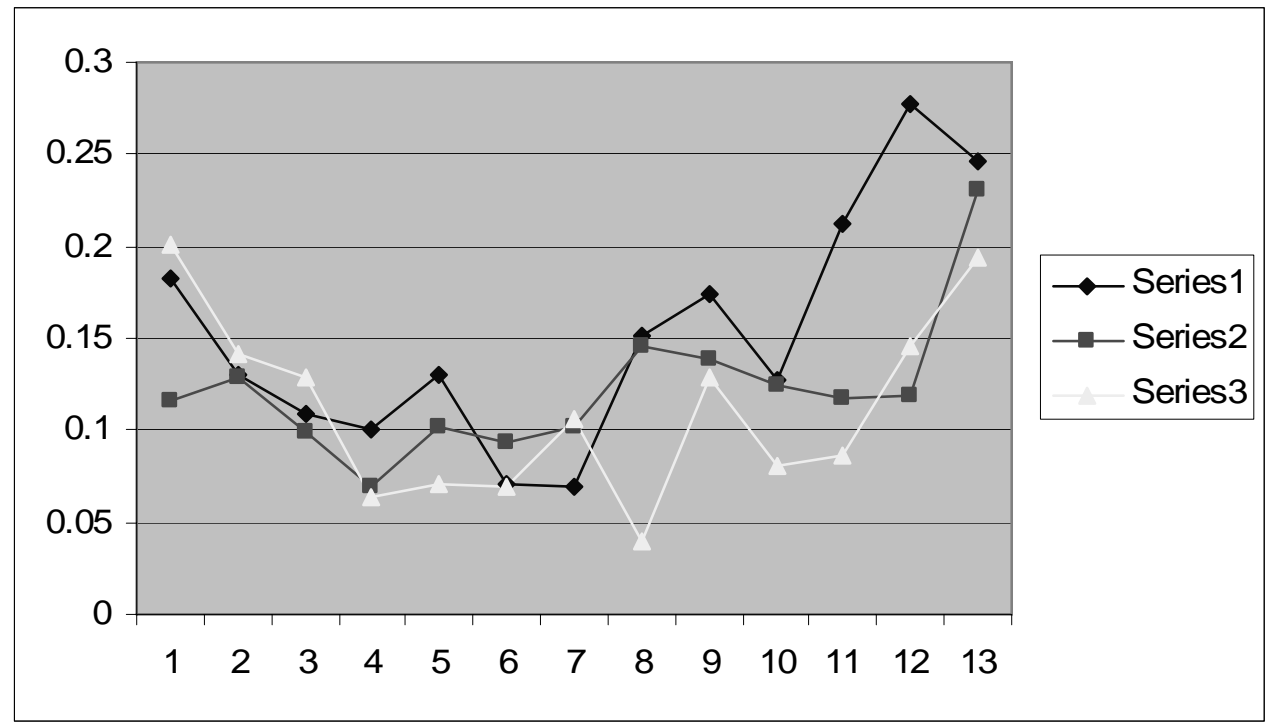


Table 2A

Major League Hitter Hazard Rates

\begin{tabular}{|c|c|c|c|}
\hline Tenure & White & Black & Latinos \\
\hline 1 & 0.182 & 0.115 & 0.201 \\
\hline 2 & 0.130 & 0.129 & 0.142 \\
\hline 3 & 0.109 & 0.099 & 0.129 \\
\hline 4 & 0.101 & 0.070 & 0.064 \\
\hline 5 & 0.130 & 0.101 & 0.071 \\
\hline 6 & 0.070 & 0.093 & 0.069 \\
\hline 7 & 0.069 & 0.102 & 0.106 \\
\hline 8 & 0.151 & 0.145 & 0.040 \\
\hline 9 & 0.174 & 0.138 & 0.129 \\
\hline 10 & 0.128 & 0.125 & 0.080 \\
\hline 11 & 0.212 & 0.118 & 0.087 \\
\hline 12 & 0.276 & 0.119 & 0.146 \\
\hline 13 & 0.247 & 0.231 & 0.194 \\
\hline 14 & 0.375 & 0.054 & 0.045 \\
\hline 15 & 0.303 & 0.194 & 0.111 \\
\hline 16 & 0.333 & 0.207 & 0.214 \\
\hline 17 & 0.375 & 0.182 & 0.250 \\
\hline 18 & 0.308 & 0.316 & 0.250 \\
\hline 19 & 0.300 & 0.182 & 0 \\
\hline 20 & 0.714 & 0.286 & \\
\hline 21 & 0.667 & 0.400 & \\
\hline 22 & 1 & 0 & \\
\hline 23 & & 0 & \\
\hline 24 & & 0 & \\
\hline 25 & & 0 & \\
\hline 26 & & 1 & \\
\hline
\end{tabular}


TABLE 3A

Hitter Career Duration Semi-parametric Analysis (1990-2004)

\begin{tabular}{|c|c|}
\hline Variable & Multinomial Logit Model \\
\hline Constant & $\begin{array}{l}-3.285 \\
(-5.76)\end{array}$ \\
\hline Black & $\begin{array}{l}-.139 \\
(1.22)\end{array}$ \\
\hline Foreign-born Latino & $\begin{array}{c}.144 \\
(1.32) \\
\end{array}$ \\
\hline Asian-born players & $\begin{array}{l}-.911 \\
(0.80)\end{array}$ \\
\hline Age & $\begin{array}{l}.196 \\
(9.93)\end{array}$ \\
\hline Slugging Average & $\begin{array}{l}-2.65 \\
(4.13)\end{array}$ \\
\hline Stolen Base Percentage & $\begin{array}{r}-.044 \\
(3.60)\end{array}$ \\
\hline Runs Batted In per game & $\begin{array}{l}-1.87 \\
(3.80)\end{array}$ \\
\hline Walks per game & $\begin{array}{c}-.021 \\
(0.05)\end{array}$ \\
\hline Strike-Outs per game & $\begin{array}{c}.763 \\
(3.36)\end{array}$ \\
\hline Hit by Pitch per game & $\begin{array}{r}-1.472 \\
(1.58)\end{array}$ \\
\hline Sacrifice Flies per game & $\begin{array}{c}.772 \\
(0.35)\end{array}$ \\
\hline Runs Scored per game & $\begin{array}{l}-2.715 \\
(5.43)\end{array}$ \\
\hline Games & $\begin{array}{c}-.0189 \\
(12.61)\end{array}$ \\
\hline Infield & $\begin{array}{c}-.441 \\
(4.41)\end{array}$ \\
\hline First Base & $\begin{array}{l}-.150 \\
(0.98) \\
\end{array}$ \\
\hline Catcher & $\begin{array}{c}-1.034 \\
(7.92) \\
\end{array}$ \\
\hline Likelihood function & -2053.62 \\
\hline
\end{tabular}

--First through fifth order tenure polynomials are also included to provide for general functional form of baseline hazard. They are jointly significant.

--The numbers in parentheses are absolute value of t-ratios. 
TABLE 3B

Pitcher Career Duration Semi-parametric Analysis (1990-2004)

\begin{tabular}{|c|c|}
\hline Variable & Multinomial Logit Model \\
\hline Constant & $\begin{array}{c}-4.82 \\
(10.20) \\
\end{array}$ \\
\hline Black & $\begin{array}{c}.073 \\
(0.40)\end{array}$ \\
\hline Foreign-born Latino & $\begin{array}{l}-.225 \\
(1.97)\end{array}$ \\
\hline Asian-born players & $\begin{array}{l}-.255 \\
(0.72)\end{array}$ \\
\hline Age & $\begin{array}{c}.170 \\
(10.14)\end{array}$ \\
\hline Earned Run Average & $\begin{array}{l}.119 \\
(6.47) \\
\end{array}$ \\
\hline Wins & $\begin{array}{l}-.148 \\
(5.60)\end{array}$ \\
\hline Losses & $\begin{array}{c}.074 \\
(3.26)\end{array}$ \\
\hline Saves & $\begin{array}{l}-.048 \\
(4.11) \\
\end{array}$ \\
\hline Strikeout-to-Walk Ratio & $\begin{array}{l}-.351 \\
(6.83)\end{array}$ \\
\hline Outs in innings pitched & $\begin{array}{l}-.0037 \\
(4.43)\end{array}$ \\
\hline Games & $\begin{array}{l}-.018 \\
(6.88) \\
\end{array}$ \\
\hline Left-handed & $\begin{array}{l}-.173 \\
(2.14) \\
\end{array}$ \\
\hline Likelihood function & -2425.16 \\
\hline
\end{tabular}

--First through fifth order tenure polynomials are also included to provide for general functional form of baseline hazard. They are jointly significant. --The numbers in parentheses are absolute value of t-ratios. 